\title{
Great Western railway electrification, UK: the key role of building information modelling
}

John Nolan

Programme Manager BIM, Network Rail, Swindon, UK

Building information modelling (BIM) transformed the delivery of Network Rail's Greater West programme, which included electrification of the Great Western railway between London and south Wales in 2019. This paper provides an insight into how BIM was developed and implemented on this $\mathbf{f 5}$ billion multi-disciplinary railway programme. In addition to significant cost and time savings, the 5 year programme's exemplary safety record can also be attributed to virtual design and construction, three-dimensional signal-sighting reviews and design reviews, all facilitated by BIM techniques and best practice.

\section{Introduction}

Network Rail's $£ 5$ billion Greater West programme included a $£ 3$ billion electrification of the UK's Great Western railway from Maidenhead to Cardiff, meaning faster, more reliable and more energy-efficient journeys for thousands of passengers and a quieter, cleaner environment for lineside neighbours. Construction started in 2014 and electric trains started running between London and south Wales in December 2019.

Network Rail's building information modelling (BIM) strategy had been in development from the outset of the original Great Western electrification programme in 2009. This evolved into Great Western route modernisation in 2014, and was later renamed the Greater West programme. Throughout this time, Network Rail was increasingly able to realise the benefits of BIM and the time and cost efficiencies this new way of working could bring.

One of the first priorities for introducing BIM was identifying the current state of information on existing projects while developing a strategic plan for future projects. Some route-clearance projects, consisting of bridge enhancement and track lowering, were already in the design and build stage, and topographical surveys and designs had already been produced. Furthermore, there were no standards, methods or procedures with regard to BIM.

\section{Initial BIM strategy}

The initial BIM strategy was based on best practice and lessons learned from the Crossrail project to build the Elizabeth line eastwest railway in London, which started in 2009 and is due to open in 2021. Crossrail was a BIM level 2 programme, with a common data environment (CDE) implemented with BS 1192 (BSI, 2007) workflows and collaborative ways of working embedded as best practice. Network Rail's information management team decided to adopt this model as best practice. A strategy was therefore conceived for BIM implementation and a campaign plan was implemented to deliver this.

During the early stages of the Great Western electrification programme, the use of drawing files and other documents being delivered by email was prevalent. Hard drives and compact discs were in constant use. Existing live projects were producing twodimensional (2D) computer-aided design (CAD) drawings in a variety of formats. These were being delivered with no version control by email. Design reviews were being produced using
Adobe portable document format (PDF) and Microsoft PowerPoint renditions.

A fundamental part of the BIM strategy was to change hearts and minds to enable BIM. Key to outlining the benefits was the production of $3 \mathrm{D}$ models. The long-term goal was to enable $3 \mathrm{D}$ model delivery for every project, with all graphical data, nongraphical data and documentation delivering version-controlled information in a CDE using Bentley ProjectWise. The off-theshelf CDE had to be configured quickly, and configuration files including drawing and model seed files, cell libraries and design file libraries were created.

Standards and procedures were produced at an early stage, including a CAD manual, survey strategy, document control procedure and $\mathrm{CDE}$ manual. The $\mathrm{CAD}$ standard was based on the Crossrail one, which mandated a 3D model deliverable from which all drawings were extracted. This requirement was added to all new contracts. Existing contracts were changed to support these new requirements, with mixed results depending on the contractor.

At stage 3 of the UK process for governance for railway investment projects (Grip), when the BIM standards were approved and the CDE was operational, a campaign plan was initiated to meet the Network Rail project teams and suppliers. A spearhead group was dispatched to meet the supply chain and give an overview of the strategy and requirements. This was followed by CDE training and familiarisation of standards for the Network Rail project teams. Project managers now had a clearer understanding of BIM requirements and started to revise existing contracts as there was an increased understanding of CAD and survey requirements and the benefits that could be achieved. The programme was moving from a PDF-only deliverable by email to a BS 1192 workflow, with all graphical data including 3D models being delivered by means of the CDE.

The BIM team consisted of the CAD manager, project engineer $(\mathrm{CAD})$, project surveyor and $\mathrm{CDE}$ administrator. The main responsibilities of the BIM team were supplier training and induction, providing governance and assurance for CAD and survey deliverables, and attending interdisciplinary design reviews. There was a daily update of trial hole locations, and site investigations and ground investigation data - including the location of installed foundations - were added to 3D models to help design and construction. As well as direct meetings with contractors, a series of webinars was initiated, outlining the benefit of point clouds and hybrid modelling. The benefits of this work can still be seen across the region. 


\section{Revised BIM strategy}

When the Great Western electrification programme became the Great Western route modernisation in September 2014, it was no longer just an electrification programme. The scope had increased dramatically to include

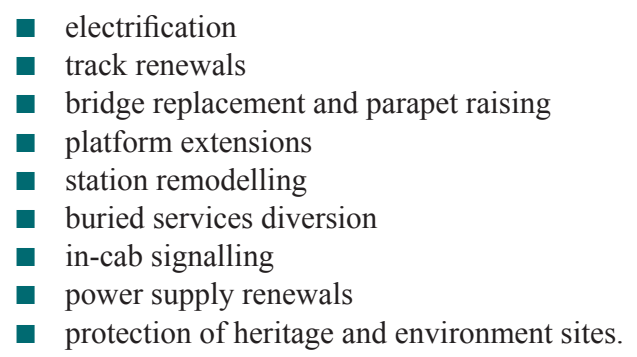

$\mathrm{ABC}$ Electrification - a joint venture of Alstom Babcock and Costain - was appointed delivery partner to the programme and with this came a major change in the BIM strategy. It involved the creation of area engineering data management teams, whose role was the creation, upkeep and use of a programme-wide 3D virtual railway model, and a change in the $\mathrm{CDE}$ configuration.

\subsection{New CDE for documents}

ProjectWise continued to be used as the CDE for graphical data and non-graphical data. However, Bentley EB information management was introduced as the system to host documentation. Once implemented, there was another campaign plan to highlight its benefits, and training and support was given in the documentation system. An information management strategy was introduced, which led to the creation of a system support team who worked with document control.

The team was established to introduce, set up and customise the documentation system. This included creating an automated system for technical queries, requests for information and non-conformance processes as well as providing a document control function. The team introduced entry-into-service and asset-management-plan workflows with virtual item structures. For the handover of health and safety files to national records, group documentation was also provided by the system.

\subsection{Engineering data management teams}

The programme was split into three areas, such that there were three engineering data management teams. These were located in the Thames Valley area (Reading office), west of England area (Bristol office) and Wales area (Newport office). They were responsible for the coordinated model within each appointed area of the route.

The area programme teams were responsible for the design content for each of their respective areas. Each team consisted of

- engineering data manager

- senior project engineer (CAD) - signal-sighting modeller

- project engineer (CAD) - 2D, 3D and 4D modelling

- project engineer $(\mathrm{CAD})$ - buried service requests and drawing creation

- project engineer (CAD) - line of route integration and interdisciplinary design review representation

- project surveyor - survey integration and site surveys to support the project.
The engineering data management teams' specific responsibilities included

- general CAD duties to meet engineering requirements, including production of $2 \mathrm{D}$ drawings, $3 \mathrm{D}$ models and $4 \mathrm{D}, 5 \mathrm{D}$ and $6 \mathrm{D}$ processes

- recording of team benefits by means of action logs

- integration and coordination of all project disciplines, including all external suppliers, contractors, maintenance and operations within the CAD model at project level

- coordinating project setup with ProjectWise administration

- supporting CAD quality assurance and any other CAD-related checks of graphical data

- providing interdisciplinary design review representation using 3D integrated models

- providing input to supplier setup, including BIM execution plan documentation

- implementing BIM compliance in accordance with regional strategy

- managing the capture of buried services data, including the creation of a single-source-of-truth CAD model for integration within the buried services strategy and permit-to-dig process

- supporting the signal-sighting committee with the appointment of virtual reality designated personnel and ensuring the creation of a virtual reality model for use in signal design and driver route-learning videos

- identifying and coordinating all survey requirements

- prioritising, planning and leading the production of all CAD team output, including presentations, animations, images, spreadsheets, datasets, drawings, models, constructability reviews, buried services management, planning applications, 4D schedule simulation, clash detection, platform standage, possessions, worksites and isolations limits, quantity and cost tracking, asset management, ground calculations, vehicle-engineering data management-path analysis, signal sighting, construction visualisation, site access, safe walking routes, project staging and hand-back (Figure 1).

The engineering data management teams were continuously building the $3 \mathrm{D}$ virtual railway model while maintaining the $3 \mathrm{D}$ model in response to ever-increasing usage requirements. The workload and size of the teams remained constant over the 5 year duration of the programme. Figure 2 shows the anticipated output for a team of six $\mathrm{CAD}$ engineers.

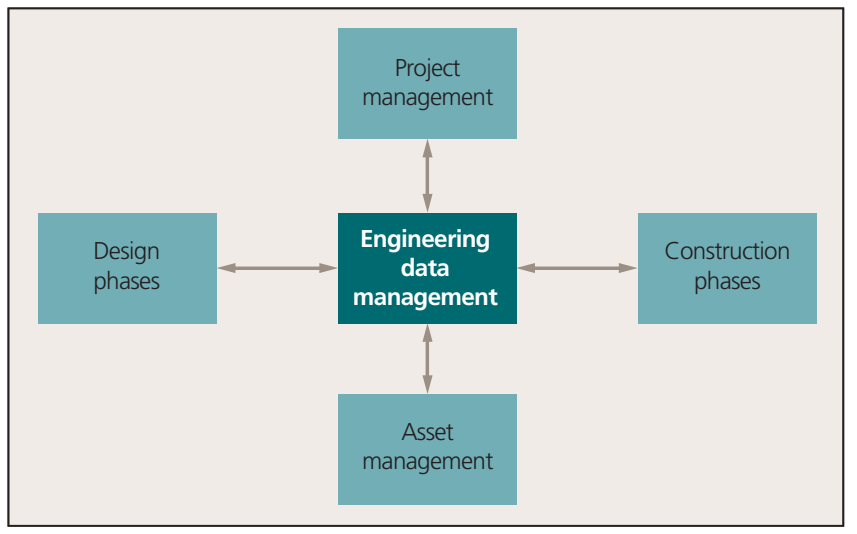

Figure 1. West of England engineering data management process 


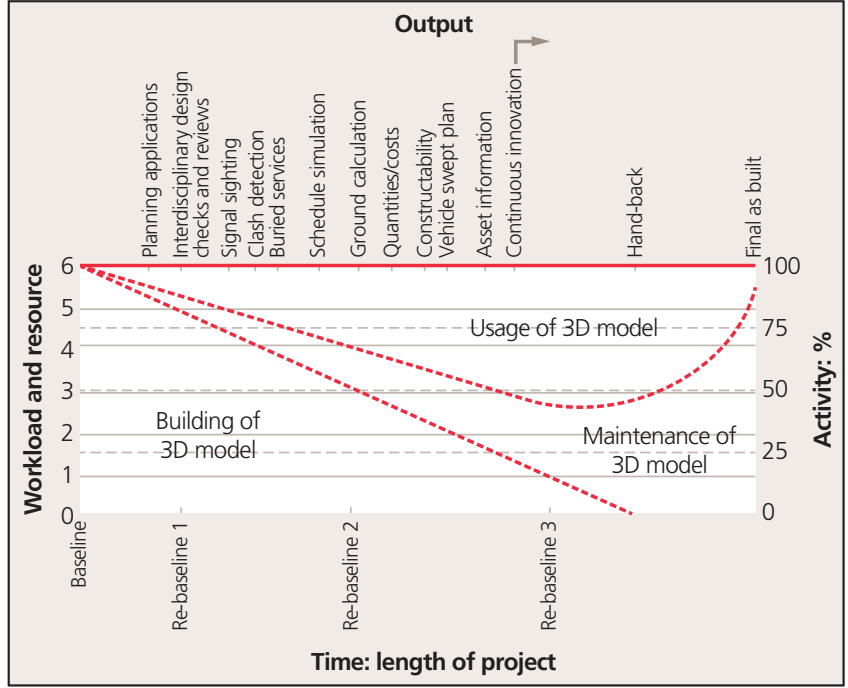

Figure 2. Engineering data management 3D model activity

\subsection{Design management - collaboration}

The lead design organisation for the programme was AtkinsParsons Brinckerhoff. Its scope was to enable the coordination and integration of engineering, designs, construction and commissioning produced by it and others and to provide ongoing site design, engineering support and validation of the works during implementation and commissioning through to entry into service.

As part of systems integration, the lead design organisation was responsible for $\mathrm{CAD}$ management and document control from tier 2 contractors. This was a mammoth task considering the size and complexity of the programme and the vast resource pool that was recruited to deliver this.

One of the major milestones was when the lead design organisation began to deliver overhead line equipment design in three dimensions. There were various attempts to apply for a derogation or to use alternative methods for delivery but, on confirmation of 2D and 3D overhead line equipment models, Network Rail was able to proceed with its modelling strategy.

The lead design organisation's BIM team worked collaboratively with Network Rail's BIM team, ensuring their respective design teams were aware of and trained in how to deliver a project to Network Rail standards. Efficient distribution of information was vital considering the design teams were located in Germany, Australia, Sweden, Malaysia and the UK.

\subsection{Construction management}

Overhead line equipment design convention for Grip 3 was to produce a layout plan with a standard walk-out distance and a known 'rail edge to face of steel'. The overhead line equipment designer would go on site and walk out each location with a wheel and subsequently check and confirm the actual distance of rail edge to face of steel. This would help to identify if there was a clash with existing lineside infrastructure, which would necessitate a design change.

A new overhead line equipment design would then be produced, providing a clear location indicating where a trial hole should be dug. The construction team would then use this information to dig

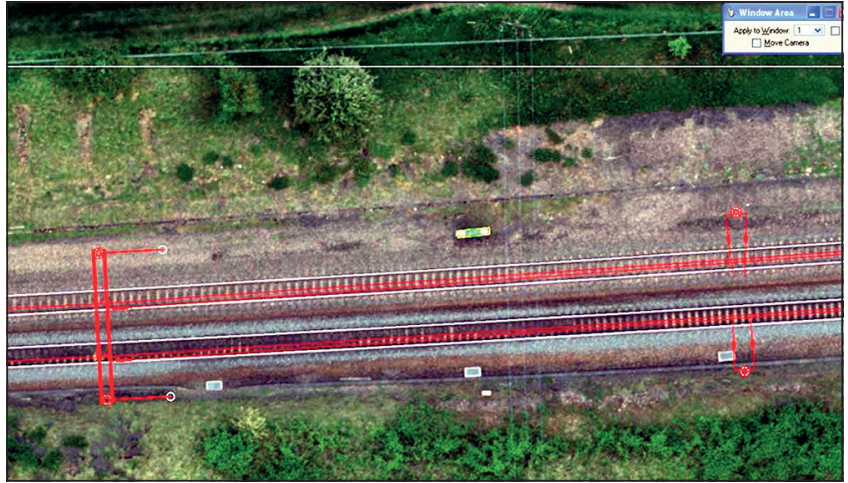

Figure 3. Example of foundation design on aerial mapping

trial holes to identify a location clear of any buried services. This as-built trial hole location would be sent to the designer, thereby confirming a safe location for the foundation design. A mast would be placed on the foundation.

The workflow of this process was as follows.

- Overhead line equipment designer produced overhead line equipment layout design.

- Overhead line equipment designer conducted site visit to check location, and location of overhead line equipment foundation was confirmed.

- Construction team went out on site and a trial hole was dug based on the overhead line equipment design to discover any buried services.

- If buried services were discovered, the overhead line equipment designer changed the overhead line equipment design to a new location.

- The process was begun again.

However, using this process could put people working on the railway at risk. This - coupled with the time and cost in producing a safe-system-of-work pack and arranging possessions - would severely impact train timetables. It was quickly identified that BIM could help the situation. Virtual design reviews could be used with aerial survey lidar data and imagery (Figure 3), which could be used to identify where troughing or any other site obstructions were. CAD models of buried services were produced to identify clear locations and additional remote surveys of complex areas were used to enhance this information, enabling lean design and first-time-right construction.

Using the point cloud data and imagery, the overhead line equipment design was delivered in $3 \mathrm{D}$ coordinates. The construction teams then went on site with satellite-positioning equipment and dug trial holes. Trial hole forms were developed that contained design coordinates, photographs, sketches and very importantly - the coordinates of clear trial holes.

The Network Rail BIM team maintained a 3D model of every trial hole location on a daily basis. This was used by the overhead line equipment designers to update their design in real time, which had tremendous time savings for the project. It also prevented the duplication of trial holes and repetitive work over a large part of the project where different teams were working. These solutions were a major step in using BIM to deliver the programme. 
The workflow of this more efficient process was as follows.

- Overhead line equipment design using 2D and 3D models were delivered using lidar survey data and buried service CAD models with assumed design rail edge to face of steel (Figure 4).

- Construction team went out on site and set out proposed design location.

- The trial hole process was subject to technical query or accepted, and feedback was sent to the design BIM process.

- The trial hole was dug with a technical query or accepted for piling, with feedback sent to the design BIM process.

- A pile was installed with a technical query or accepted as-built, with feedback to the design BIM process.

This process was repeated until the design was fully cleared for the installation of steel work.

At this stage of the project the BIM team began to plot geotechnical, environmental and ecological data into the model. Workshops were held where geotechnical engineers would sit with construction managers and overhead line equipment designers. In these workshops, visual information combined with route videos enabled the team to pinpoint what type of foundations could be installed based on geological awareness. Ecological and environmental information was intelligent and searchable.

\subsection{Virtual overhead line equipment construction}

Working from Network Rail's high-output operations (Hops) base in Swindon, the $£ 40$ million Hops train installed the overhead line equipment. It worked for $7-8 \mathrm{~h}$, six nights a week, completing around $1.6 \mathrm{~km}$ of overhead line equipment each night.

Every Thursday, an all-day meeting was attended by the overhead line equipment construction team. The following week's work was planned using $2 \mathrm{D}$ and $3 \mathrm{D}$ BIM models run with the scheme plan. This helped to identify road-rail access points, directions of travel for the Hops train and cross-over points, all of which gave a detailed plan for how best to install the overhead line equipment. This was a very successful use of BIM as it greatly enhanced overhead line equipment construction. As a result of the
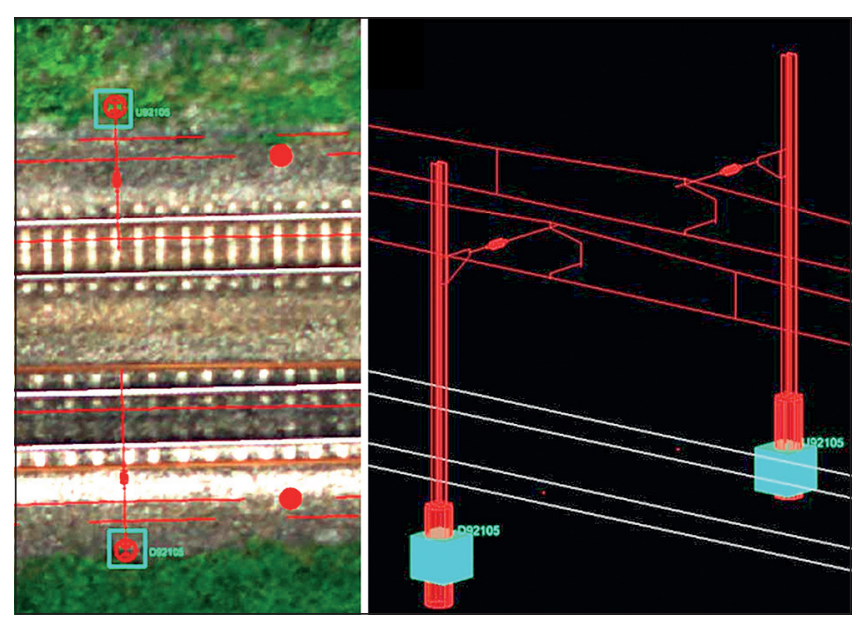

Figure 4. Early example of design integration of trial holes with overhead line equipment design process, there was also an as-built $3 \mathrm{D}$ model so everyone on the programme knew what had been installed each week.

\section{Overhead line equipment design software}

At the start of the electrification programme, Network Rail trialled Power Rail Overhead Line software but found it could not be configured with its overhead line equipment series 1 design. The programme then looked to the lead design organisation to provide an overhead line equipment design solution that would produce drawing layouts and cross-sections to Network Rail standards in ProjectWise, but it was not until much later in the programme that an in-house solution based on Bentley MicroStation was developed.

In the meantime, a decision was taken to use Furrer+Frey Elff software as it was used for the original design of overhead line equipment series 1. Based on Autodesk AutoCAD, the software had $2 \mathrm{D}$ and $3 \mathrm{D}$ outputs but this was of wireframes rather than surface models. Wireframes are not suitable for signal sighting as the driver's eye in the models can see though the overhead line equipment structures, which defeats the purpose of clash detection for signal sighting. Elff was therefore reconfigured to have the correct output, enabling Grip stage 5 overhead line equipment structures and smallparts steel to be modelled in three dimensions (Figure 5).

One of the main challenges for Network Rail was to demonstrate to the supply chain that it had to produce drawings and models from Elff, delivered in DGN drawing format in ProjectWise, using drawing and model seed files. The seed file title blocks were linked to ProjectWise metadata.

Examples of configuration requirements that had to be checked prior to agreement of Elff included the following:

- ProjectWise integration

- production of Network Rail-compliant 2D model files (Figure 6)

- production of Network Rail-compliant CAD layout drawing files (Figure 7)

a production of Network Rail-compliant cross-section drawings

- production of Network Rail-compliant 3D model files

- production of other Network Rail-compliant CAD drawing seed files

- PDF renditions graphics tests

- conformance to Infrastructure Projects Western and Wales CAD standards

- level of detail

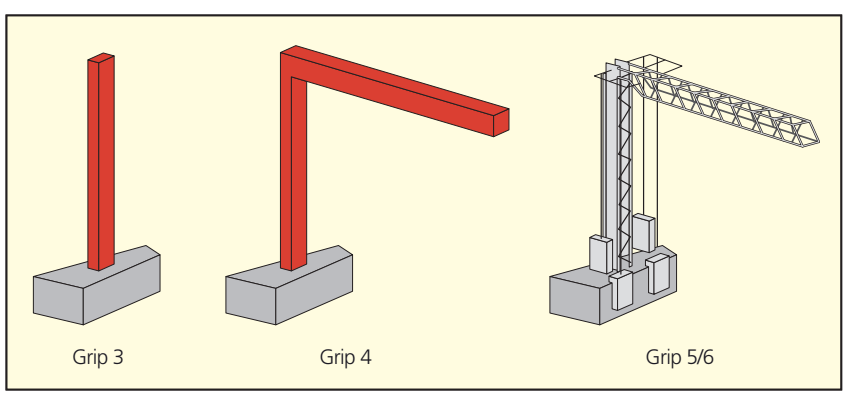

Figure 5. Grips 3-6 level of detail 
- CAD quality assurance

- overhead line equipment library location - where was this stored on ProjectWise

- files' size and display

- whether 2D and 3D files were integrated with Network Rail signal-sighting models and interdisciplinary review models

- what materials/textures were attached to the overhead line equipment 3D model

- visibility of wires in Network Rail's CAD software

- bill of quantities - how these were produced and displayed

- foundation designs (pile, concrete and pad) - whether these were a built-in design process or a separate process, and how these were displayed in 2D and 3D models

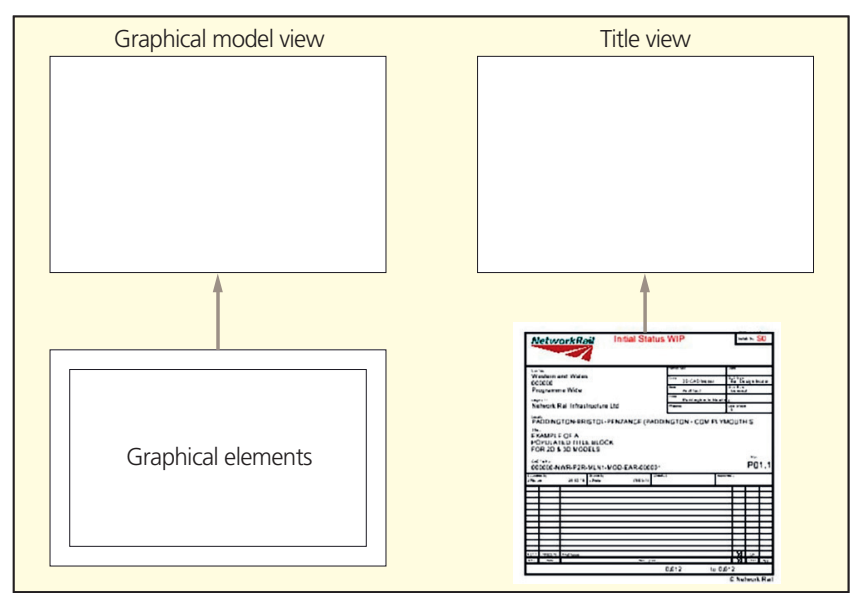

Figure 6. Network Rail 2D and 3D CAD model configuration
- compliance with Network Rail asset requirements

- how technology could be saved and reused if a different supplier used alternative software

- whether data could be converted between grids using SnakeGrid convertor or a manual procedure, and whether any accuracies were lost

- what measures were made to have a laptop with the software for the project team for any future work and changes after the project

- training and costs.

\section{Volume strategy}

The Greater West programme has electrified around $1000 \mathrm{~km}$ of railway between London and Cardiff. This huge project involved installing 22000 piles, masts and associated wiring. As already mentioned, the programme was divided into a series of route sections and split into three areas as follows:

- Thames Valley area - Reading station area remodelling, Oxford area renewal of signalling, Reading outer renewals and immunisation, Swindon B, Oxford corridor and western EMU deployment; route sections RS1, RS1A, RS2, RS2A, RS3, RS4, RS4A, RS5A\&B, RS6D, RS7C and RS11C; MLN1 - Ruscombe to Uffington, HEN - Twyford to Henley, RDG2 - Winnersh to Reading, BHL - Reading West to Newbury, DCL - Didcot to Heyford, OXD - Oxford area only

- West of England area - Swindon panel A signal box signalling renewal, Bristol area signalling renewals and enhancement, Filton bank four-track, Bristol east, Bristol Temple Meads station and Bath corridor; route sections RS5 (West), RS6 and RS7; MLN1

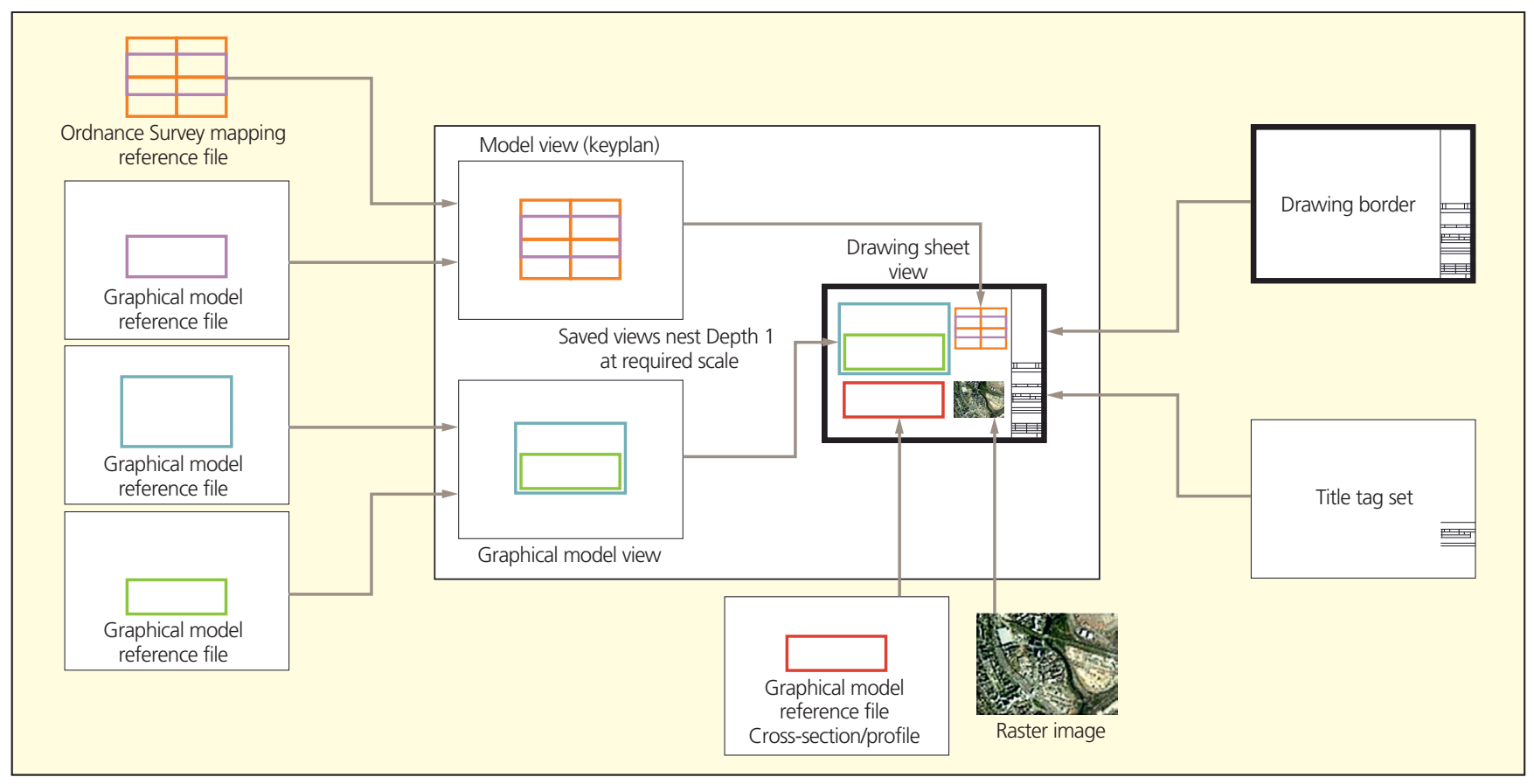

Figure 7. Network Rail CAD drawing configuration 
- Uffington to Patchway, SWB - Wootton Basset to Bristol Parkway, BSW - Bristol Temple Meads to Bristol Parkway

- Wales area - Cardiff area signalling renewals, Newport area signalling renewals, South Wales immunisation; route sections RS6P, RS8, RS9; SWM2 - Bristol Parkway (overhead line equipment) to Cardiff.

Each route section was subdivided into an overhead line equipment construction unit, which was determined by an overhead line equipment layout plan extents (typical distance of $1 \mathrm{~km}$ on open route). These locations were used to plan signal sighting, design reviews and construction. For hand-back and close-out of the programme, construction units were used to determine how assets were handed back.

\section{Modelling strategy}

Early planning for BIM and supplier engagement on the electrification programme started to see success. The supply chain began to deliver CAD drawings in ProjectWise, which included a version-controlled 3D model in the CDE.

The first example was Shrivenham Road Bridge design integration (Figure 8). There was concern from the Network Rail signalling project engineer that the proposed bridge would impact the sighting of a signal further down the route. A basic 3D model was produced using a survey of the signal, the digital terrain model and track produced from lidar surveys. This data was successfully integrated with the proposed bridge design, with a sightline from the signal to the driver's eye view reading distance. This successfully identified a clash, which enabled contractor Amco to redesign the structure before installing it on site.

With the early success of Shrivenham Road Bridge, the Network Rail signalling engineers wanted to take full advantage of the BIM process. The project team were in favour of using third-party contractors to deliver signal sighting using augmented reality from cab ride videos. This signal-sighting process would have had a 2 week turnaround per signal change, with an estimated cost of $£ 5000$ per signal. Original third-party costs were $£ 1$ million with $£ 5000$ for every signal change once this threshold was met.

Despite some objections, the signalling project engineers understood the time and cost savings that could be achieved using 3D models integrated with overhead line equipment designs for a programme of this size. During this debate, the project team proceeded to produce hybrid models of the route which contained 3D models, topographical surveys and lidar data. With an increase in resources for the engineering data management teams, these

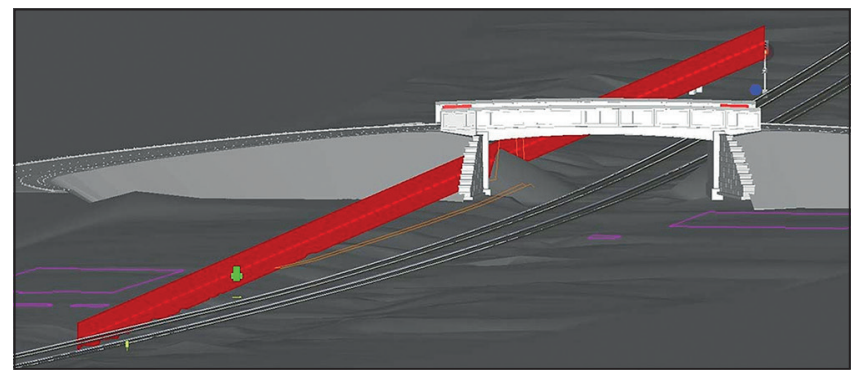

Figure 8. Early example - Shrivenham Road bridge sighting were quickly transformed into a 3D virtual railway for signal sighting for the programme extents.

Stakeholder engagement was key to the process. Train and freight operating companies and signal-sighting chairpersons began to see the value of using a 3D model that was faster, highly accurate and more intuitive than existing processes.

A signal-sighting model was produced for each route section. It contained reference files relating to every element of the work, including both existing and proposed information for the purpose of visualising and coordinating signal sighting. All models were placed relative to an engineer's line reference and metreage. The model aligned with the integration model as a single source of truth and contained the following data as a minimum: track, signalling, overhead line equipment, lineside equipment, mechanical and electrical services, utilities (also known as buried services), civils structures, ground profiles, ballast profiles, buildings, signs and the master reference chainage and mileage. The signal-sighting model was an accurate interpretation of the engineering design and was rendered with actual building textures to provide a virtual reality model (Figure 9).

\subsection{Signal-sighting meetings}

Figure 10 shows the signal-sighting meeting room configuration. Screen 1 was used to display, manipulate, change, zoom and view the 3D virtual reality model of the specific asset being assessed. Screen 2 was used to display ProjectWise, Track Video, Omni Surveyor, Bentley EB, 2D layouts and/or other useful data available by way of the Network Rail integrated management system, signal-sighting forms, scheme plans, minutes of meetings and any other supporting or live-created documentation. Screen 3 was used to display and manipulate, change, zoom and view the $2 \mathrm{D}$ virtual reality model of the specific asset being assessed.

By combining 2D models in 2D plan view and 3D models of driver's eye view, the benefits of using BIM were realised. Signal sightlines could be added by the CAD modeller to demonstrate clash detection and signal obscuring visually. Signals could be amended, distances changed and signal head arrangements could be reconfigured in a few minutes. At its peak, 43 signals were sighted, approved and signed in one day using this process. Signal

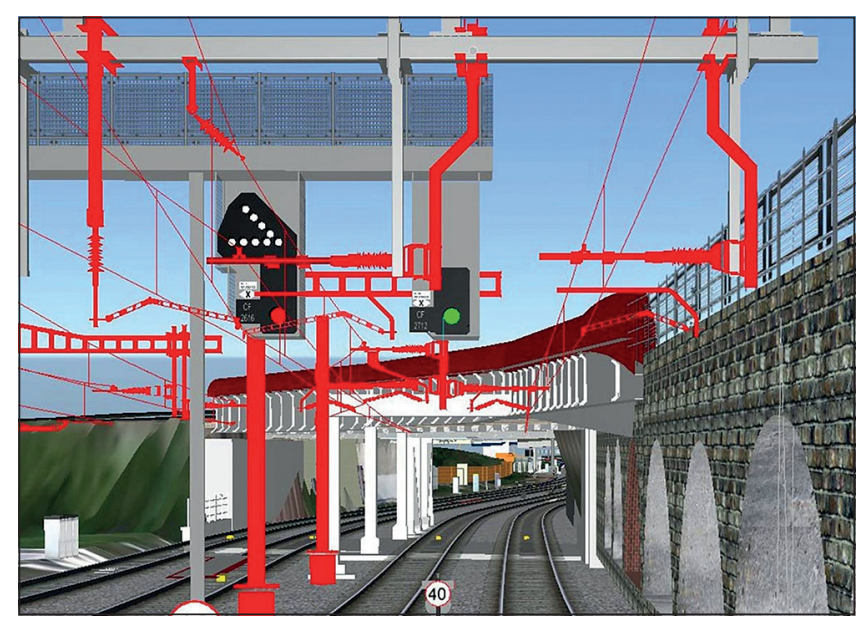

Figure 9. Example of signal sighting - Cardiff intersection bridge showing two versions of overhead line equipment design (current version in red) 


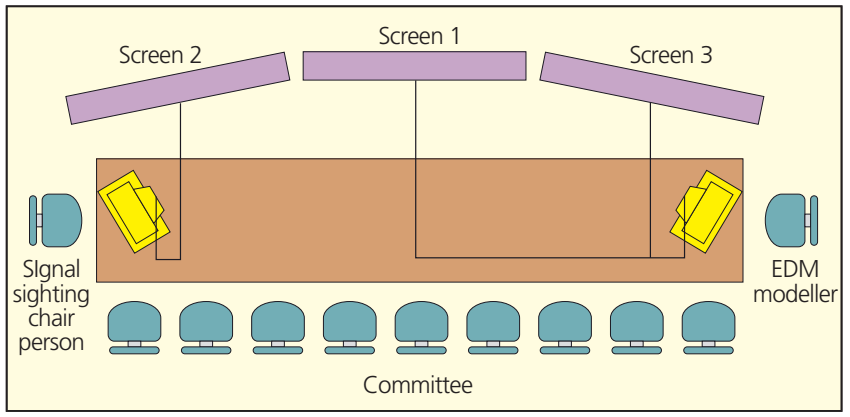

Figure 10. Signal-sighting meeting room configuration. EDM, engineering data manager

sighting using the $3 \mathrm{D}$ virtual railway model is still conducted from Paddington to Cardiff and Bristol Temple Meads stations.

Sign sighting and level-crossing assessments were all conducted using the 3D model (Figure 11).

\subsection{Transmittal of information for signal sighting}

For every signal-sighting review, 2D and 3D models had to be formally submitted to the project at a shared state. Track-alignment files were also required for any changes to the track as the driver's eye view is along the left-hand rail. CAD model title block revision dates and status were checked, validated and recorded in the meeting minutes.

\subsection{Integration model}

An integration model was also produced for each route section. It contained reference files relating to every element of the work, including both existing and design information for the purpose of coordination and clash detection and for use at interdisciplinary design reviews (Figure 12).

- Track - a single staging model was developed using existing, design and as-built surveyed data, containing line strings for all alignments, switches and turnouts and point number information (for signal sighting the rendered version was used).

- Signalling - consisted of two models, an existing model and a design model, each containing signals, gantries, train protection and warning system and automatic warning system magnets, signal post telephones, axle counters and speed signs.

- Overhead line equipment - a single master model containing nested references of the design models showing foundations, legs, booms, signalling power supply and wiring.

- Lineside - a single staging model was developed using existing, design and as-built surveyed data containing, but not limited to, the following existing, proposed and modified data: lineside equipment, bike stands, buildings within the Network Rail boundary, drivers' cabins, fuel areas, seating, containers, walls, bases, cable bridges, cleaners' cabinets, drivers' walkways, fences, acoustic barriers, barriers, fences, handrails, high-voltage marker posts, Japanese knotweed burial chambers, king posts, lockable barriers, pipe racks, platforms, retaining walls, road speed humps, road protection plates, road-rail access points, sheet piling, split ducts, external stairs, vent pipes, walking routes, cable ducts, closed-circuit television (CCTV) masts, customer information screens, derailers, distribution boxes, drainage, hollow bearers, isolation boxes, light bollards, lighting columns, location

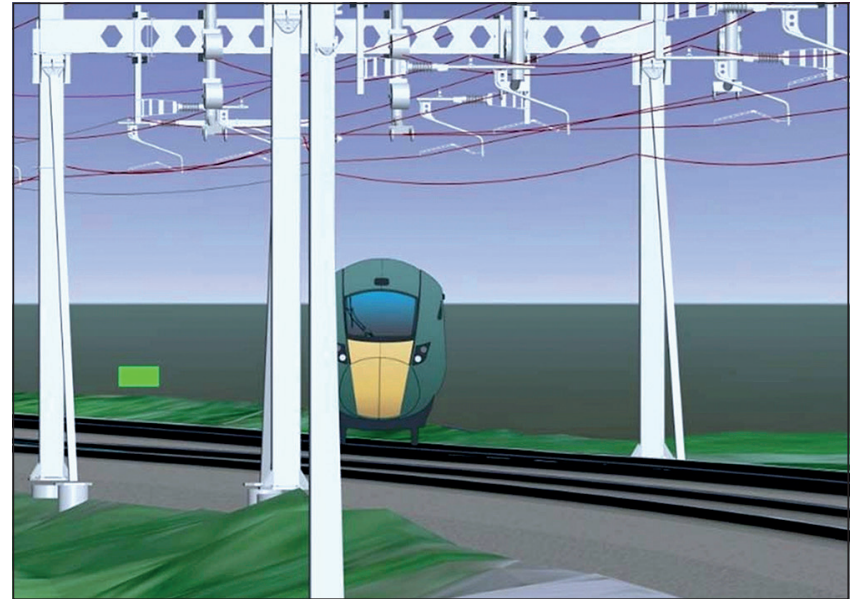

Figure 11. Example of level-crossing assessment

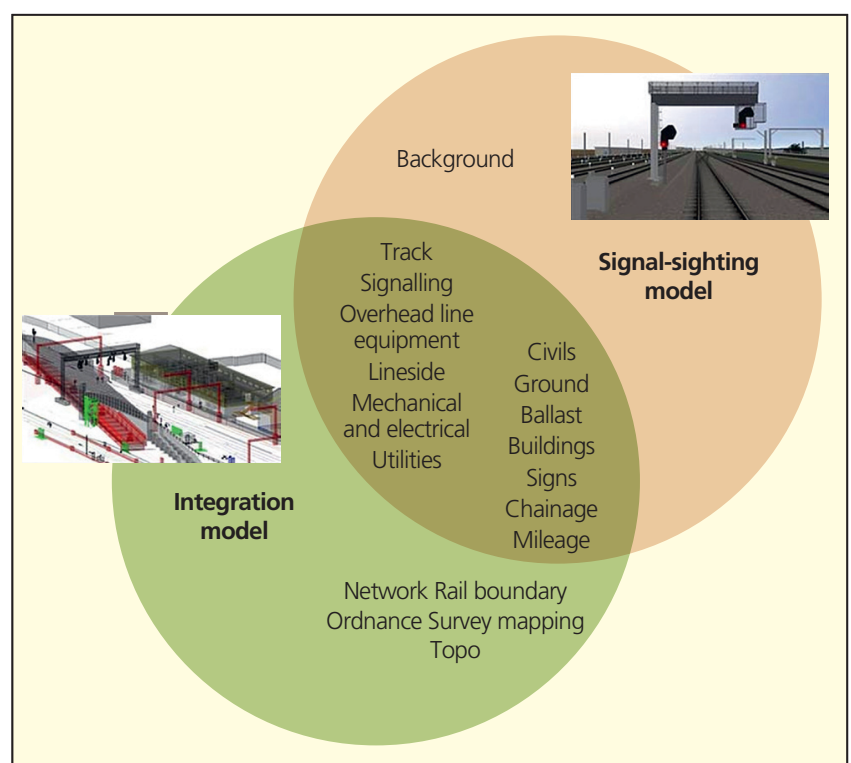

Figure 12. Model relationship with signal-sighting and integration model

cabinets, long bearers, object controllers, overhead line equipment protection bollards, platform pit numbers, points clips cabinets, points heating cubicle, points heating transformers, points motors, poles, probes, power supply points, pylons, pylon cables, radio masts, rail lubricators, relocatable equipment buildings, relay rooms, radio frequency identification, cable routes, signage, transformers, troughing and under-track crossings.

- Mechanical and electrical - consisted of two models, an existing model and a design model, each containing all mechanical and electrical services including lighting, customer information panels, customer information service posts, CCTV cameras, speakers, sockets, trunking, cable trays, distribution boxes, fuses boxes, water pipes, drainage pipes, radiators, ventilation ducts, air conditioning units, grilles, valves, pumps, generators, chiller units, dampers, vents, tanks, transformers and control panels. These models were primarily included for work involving station renewal. 
- Utilities - a single master model including the following data: gas pipes, high- and low-voltage electrical cables, historic cable routes, water pipes, culverts, surface and track drainage pipes, foul and clean sewers, telecoms cables, signalling and telecoms cables, troughing, under-track crossings, CCTV cables, signalling cables and trial holes.

- Civils - typically consisted of three models - a removed model, a remaining model and a proposed model - including the following data: platforms, floors, walls, windows, doors, ceilings, floor slabs, columns, parapets, beams, stairs, skylights, roofs, drainage gulleys, seats, lamp posts, handrails, escalators, lifts, canopies, ladders, foundations, piles, retaining walls, toilets, kiosks, partitions, bridges and stations.

- Ground - a single triangulated master model derived from survey data, decimated to a workable level without loss of detail. There was one ground model per Ordnance Survey mapping tile. On the signal-sighting model, the aerial imagery was draped onto each surface tile.

- Ballast - a single triangulated master model derived from survey data, decimated to remove undulations that could obscure any other data including track, troughing and groundlevel lineside equipment. There was one ballast model per Ordnance Survey mapping tile.

- Buildings - a single master model for neighbouring buildings outside the Network Rail boundary. The level of accuracy was dependent on use. It was derived from Ordnance Survey mapping using extruded shapes with estimated or calculated height and elevation, and rendered in the signal-sighting model.

- Signs - consisted of two models - an existing model and a design model - each containing signs, posts, fixings, cantilevers, hangers and so on. These models were primarily included for work involving station renewal.

- Chainage - a single master model for reference chainage containing chainage markers, chainage text and so on.

- Mileage - a single master model for milepost locations containing 2D mileposts, milepost text showing where known, easting and northing coordinates, milepost name and so on.

- Network Rail boundary - a single master model of the Network Rail property boundary. It was derived from the geographic information portal and traced using Ordnance Survey mapping.

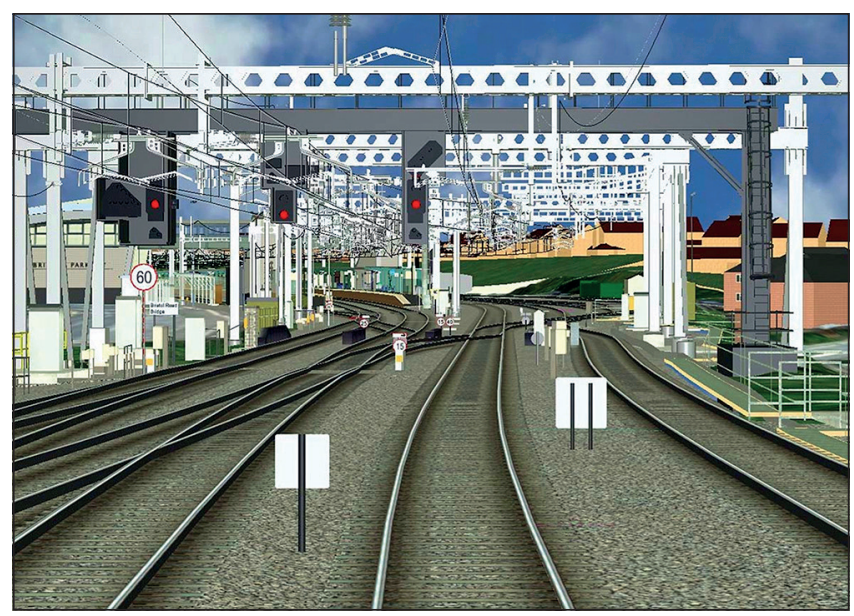

Figure 13. Overhead line equipment design review at Bristol Parkway
- Ordnance Survey mapping - a single master model containing nested references of the Network Rail Ordnance Survey mapping files. This file was attached to the integration model and signal-sighting model as a nested reference.

- Topo - a single master model containing all of the topographical elements as provided by third-party surveys or the engineering data management project engineer (survey).

- Background - a single master model containing all of the vegetation elements, including trees. This was used for the signal-sighting model only.

- Textures - a series of JPG and TIF image files derived from photographs for the purpose of rendering 3D model elements. They were used for the signal-sighting model only.

\subsection{Interdisciplinary checks and design reviews}

For every interdisciplinary check and interdisciplinary review, the following information was required to be formally submitted on a transmittal:

- CAD drawings, 2D and 3D CAD model files

- design risk assessment

- PDF renditions of drawings and model files

- interdisciplinary check and interdisciplinary review certificate ready for signatures.

This information was required 10 days in advance, so the models could be updated, and all checks carried out. Version control was mandatory and CAD drawing and model title blocks were reviewed.

If the information was incorrect, the submission was rejected to be resubmitted - to accept it would have led to incorrect meeting minutes. There were also instances early on where a review was taking place, only for the engineering data management team to identify that the drawings were still open in ProjectWise (i.e. still being worked on). The project engineer would then run the integrated model for this meeting and conduct clash detection and walk-throughs, check dimensions, identify buried services and so on, and a model was saved as a record of this review (Figure 13).

\subsection{Driver route-learning videos}

The engineering data management teams' updates of the integration models and signal-sighting model were ultimately used to provide driver route-learning videos. Historically, these were being produced using cab ride video augmented reality. However, there were limitations to this technology in placing geospatial overhead line equipment designs and the series of changes.

The Bristol area signalling renewal enhancements project produced driving route-learning videos using a virtual 3D model. This was in partnership with track-access solutions and was a very cost- and time-effective way of producing these deliverables. The programme now had an established BIM process from using survey baseline data to creation of a virtual 3D railway model, which could be used for stakeholder engagement, option selection, interdisciplinary design reviews, signal sighting and driver route learning (Figure 14).

\section{Survey management}

A large number of surveys was produced throughout the programme. Traditional surveys were conducted when required 
for civil enhancements. The primary method of data collection for overhead line equipment was both aerial lidar survey and Fugro Rila train-mounted surveys. The use of this technology had the biggest overall impact on the project. In addition to this, primary, secondary and tertiary ground control was installed across the project extents utilising SnakeGrid.

\subsection{Aerial lidar survey}

In Grip 2, the programme commissioned an aerial survey produced by Fugro. This was delivered in OSGB36(02) survey grid for the entire length of the project and spanned $40 \mathrm{~m}$ each side of the track centreline. The deliverables were point cloud data in POD/LAS format (Figure 15) and high-resolution aerial imagery (Figure 16).

Feature-extracted line strings, which contained track, signals, bridges and lineside assets, were extracted. This provided a considerable set of information, the benefits of which were realised during the project. This was the main set of survey data used by the designers for Grip 5/6.

\subsection{Survey grid}

The Fugro data deliverable was produced in OSGB36(02) grid and achieved the required level of accuracy for overhead line equipment design tolerances. The decision was made to produce all overhead line equipment designs in OSGB36(02) grid and this requirement was added to all overhead line equipment contracts. Interface to all engineering aspects of the project was enabled using transformation software (DHP11 and FME) to allow integration with engineering works.

The majority of non-overhead line equipment works were carried out in UCL SnakeGrid, allowing 1:1 site setting out for construction purposes. These were then transformed by the engineering data management teams to allow integration with the overhead line equipment design.

\subsection{Route clearance de-vegetation}

One early use of BIM was ascertaining where to cut back vegetation that would impact overhead line equipment

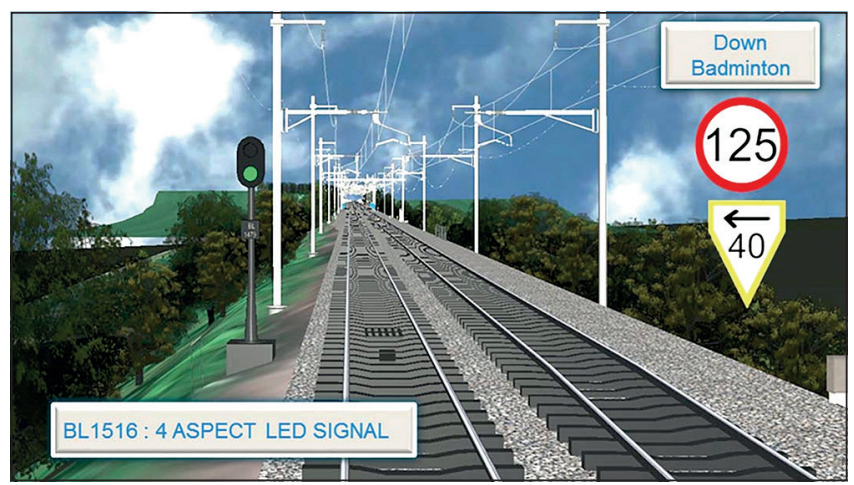

Figure 14. Example of early driver route-learning video construction. Point cloud was placed in a 3D model with a surface offset from the left-hand rail (Figure 17).

Using clash detection, the team could identify areas of the rail network where de-vegetation was necessary. This helped contractors plan their works more efficiently.

\subsection{Rila train-borne survey}

The Rila platform measured relative and absolute track position, track geometry and the wider rail corridor to millimetre accuracy. Train-mounted Rila systems quickly and efficiently measured the track and rail corridor, avoiding disruption to rail services and removing the risks associated with trackside working (Figure 18).

The project commissioned Rila surveys for its extents from Maidenhead to Swansea. This data was used extensively by south Wales electrification for design purposes, having been commissioned to be delivered for the design. Thames Valley and West of England overhead line equipment designers used gauge clearance output data and this was used to great effect answering tender queries (Figure 19).

Rila surveys were used by the engineering data management teams to produce highly accurate $3 \mathrm{D}$ models. This was an accurate refresh of the current state of the programme. Rila surveys are now approved by Network Rail for gauge clearance on open routes and in station areas.

\subsection{Engineering data management project surveyors}

The engineering data management project surveyors provided support to the engineering data management teams and all engineering and construction disciplines in the survey and capture of all existing, as-built data and inputs, and oversaw any third-party survey specification (see Figure 20). Interface with other surveyors was critical to establish a controlled approach and manage the survey strategy.

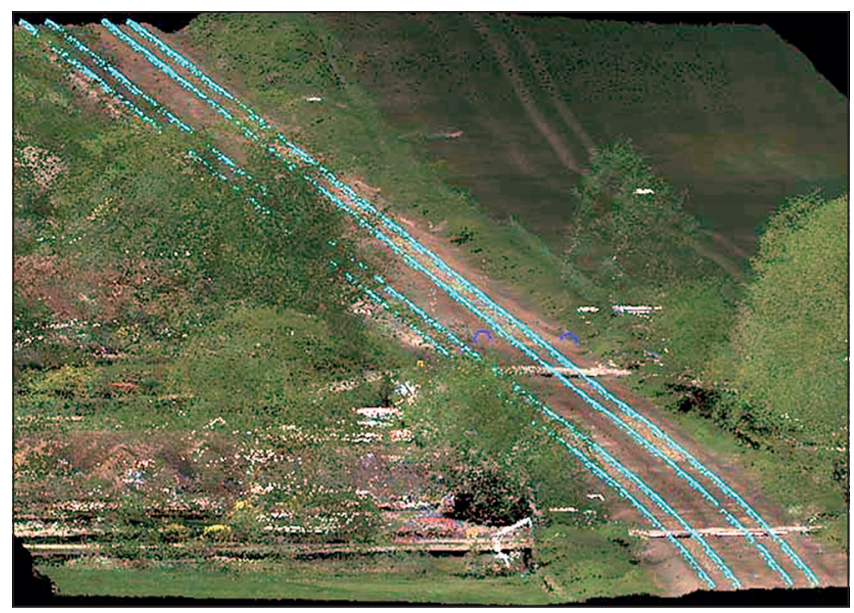

Figure 15. Example of aerial lidar survey

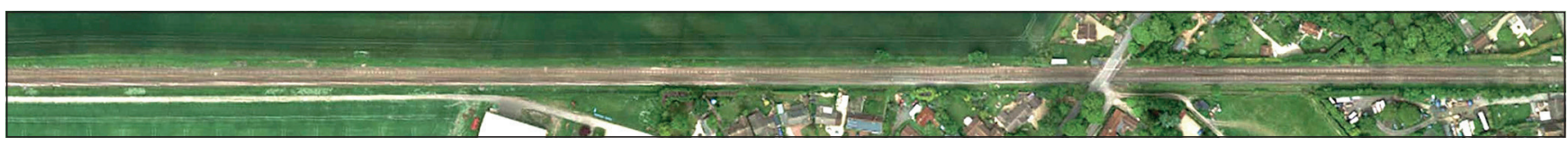

Figure 16. Example of aerial survey imagery 
Great Western railway electrification, UK: the key role of building information modelling Nolan

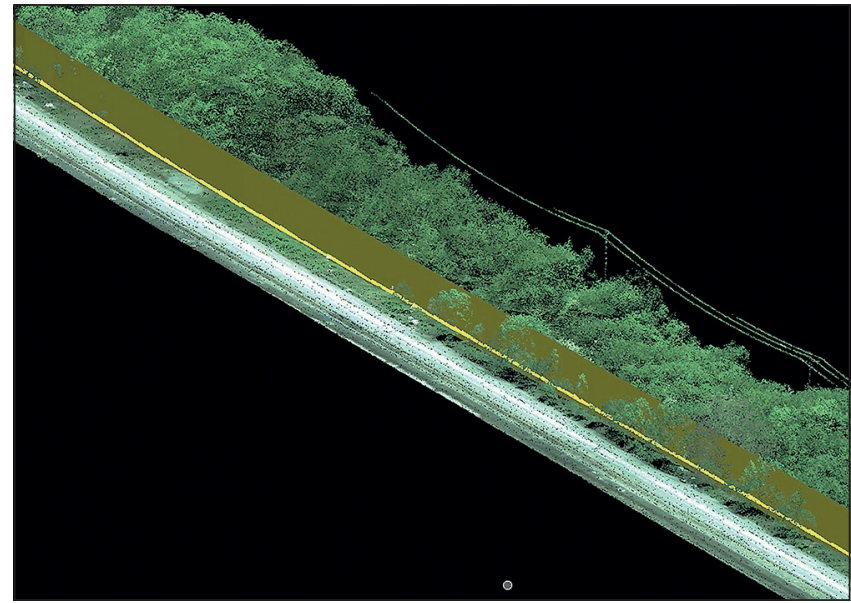

Figure 17. Example of de-vegetation corridor

The surveyors' responsibilities were to

- manage the master survey register

- manage the federated survey model

- ensure all surveys were produced in SnakeGrid

- be aware or notified of all current and proposed surveys, so preventing the duplication of work

- ensure all surveys complied with Wales and Western survey standard WAW IMS 866 (Murray, 2014) and were produced in accordance with Wales and Western CAD standards

- ensure no local surveys were produced, but if a derogation was agreed, check local survey setting-out coordinates were recorded with ETRS89 coordinates and local survey control.

The use of SnakeGrid on the programme allowed a seamless design and engineering interface on a multi-disciplinary project. One of the misconceptions regarding railway infrastructure survey is that it has a lifecycle of 6 months. This is only applicable to track due to tamping and other activities that happen outside the region. Surveys inside Network Rail's land boundary are still applicable until those assets are altered. A quick visual check can identify what changes there have been to an area; if there are not new assets then the survey is still valid.

Site investigation and ground investigation, once saved in the $\mathrm{CDE}$, can be used for any future projects until a new enhancement project changes the ground profile. Continual updates from as-built surveys were captured by the engineering data management survey team. This allowed for swifter progress in interdisciplinary checks and reviews, signal-sighting issues and so on. In-house survey data capture allowed designs to progress without costly delays.

\section{BIM benefits - interfacing projects}

\subsection{Filton four-track project}

The Filton four-track project and Dr Days to Filton Abbey Wood capacity improvement consisted of

- an additional platform at Filton Abbey Wood station with a ramped footbridge access

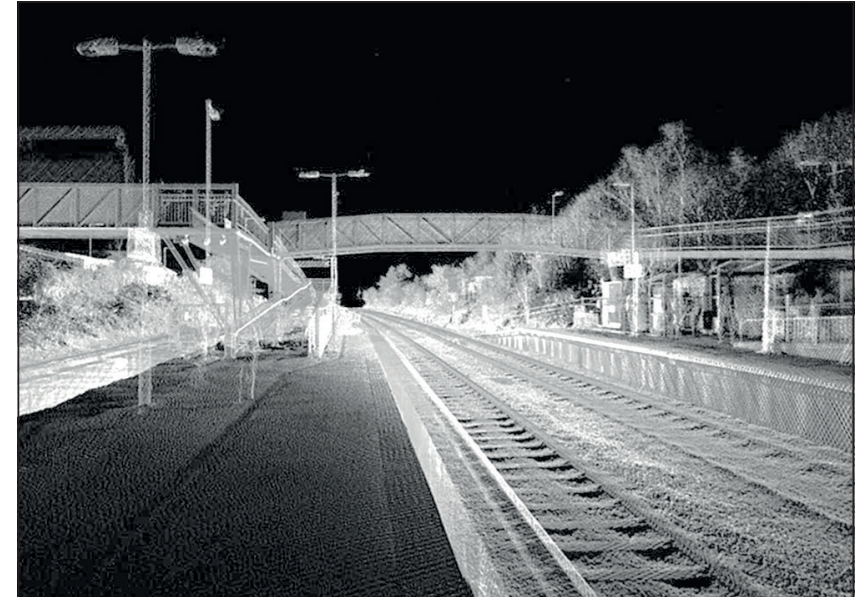

Figure 18. Example of train-mounted Rila survey

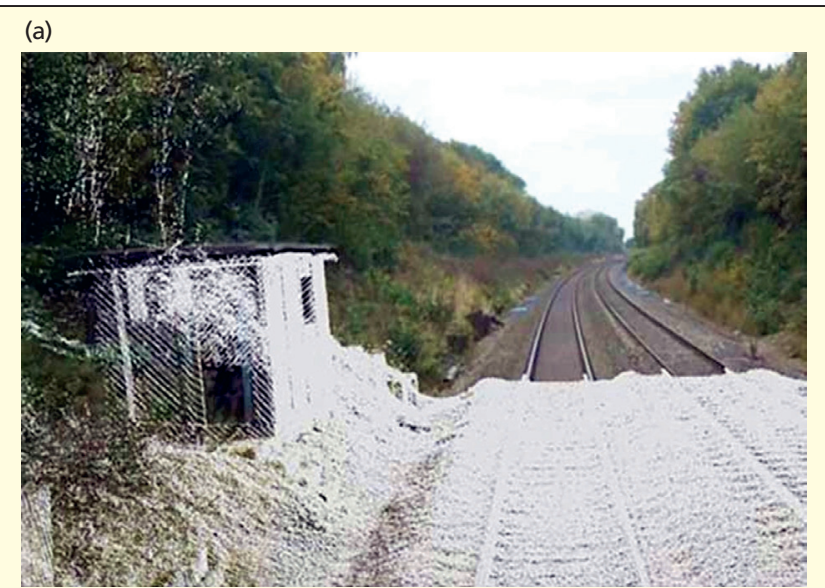

(b)

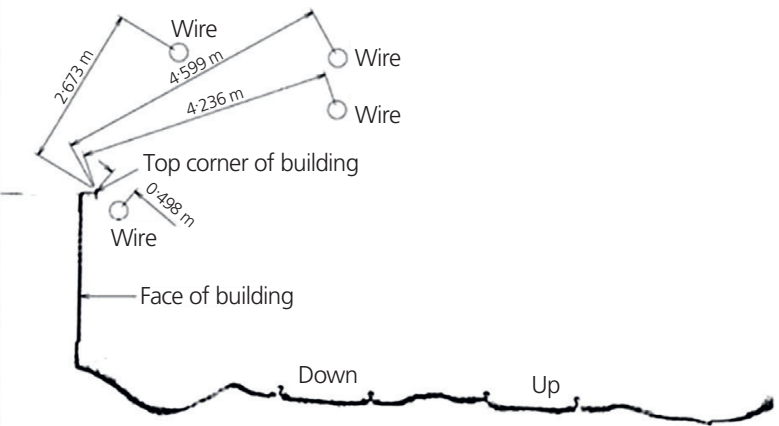

Figure 19. Example of clash avoidance check for former bothy structure using Rila point cloud data

- full reconstruction of over-bridges (Stapleton Road viaduct, Narroways Hill footbridge and Stanley Farm footbridge, Church Road, Easton Road, Constable Road and Ashley Hill footbridge) and six bridge parapet upgrades 
- footbridge extension with disability ramps at Stapleton Road station

- embankment stabilisation at Muller Road and Ashley Hill

anchored gabion wall and re-grade at Horfield

- new toe wall and re-grade at Narroways cuttings

- re-positioning of two rail communications masts.

For the Filton four-track project, a wide range of BIM activities took place. The information model was stored in the CDE. Point cloud scans were produced for all assets, and 3D models were developed for existing structures and, for the design stage, 3D models of the proposed structures (Figure 21). This information model was then used to enhance the design process. Using this supplier information in conjunction with Rila surveys, the engineering data management team produced a 3D virtual model from Bristol Temple Meads to Bristol Parkway (Figure 22).

4D modelling was also used on the project. The engineering data management team began using Bentley Schedule Simulation, while Autodesk Navisworks was used for major works. Narroways footbridge, Stapleton Road viaduct and Eastern Road Bridge were modelled in $4 \mathrm{D}$ to inform key stakeholders (Figure 23).

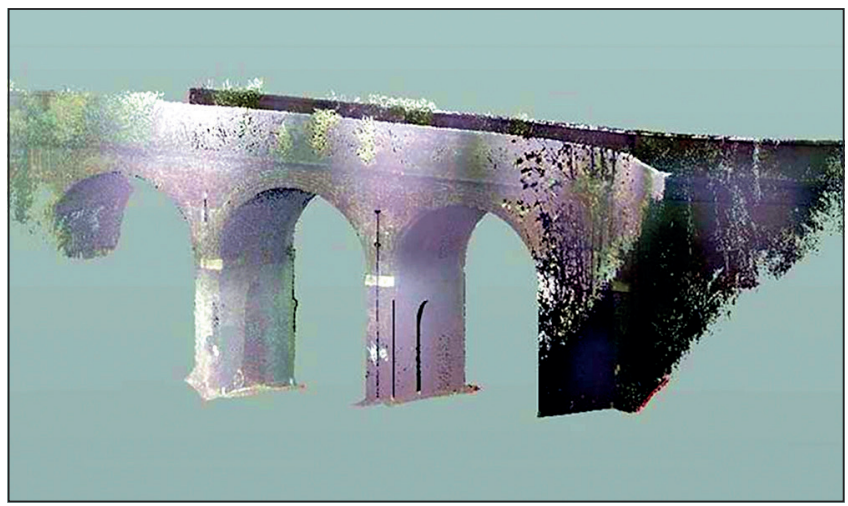

Figure 20. Example of engineering data management survey point cloud

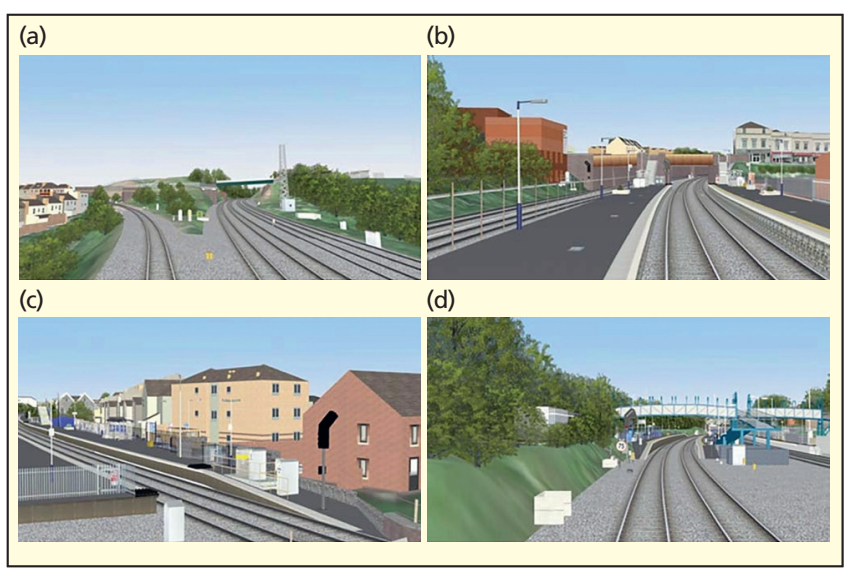

Figure 22. Example of Filton four-track virtual model: (a) Narroways footbridge; (b) Lawrence Hill station; (c) Stapleton Road station; (d) Filton Abbey Wood station

\subsection{Bath station upgrade}

A 3D model was produced for Bath station. This was used for engagement with the community by identifying Network Rail's proposals, design integration with signal-sighting and interdisciplinary reviews, and a 4D model for planning the works on site.

Bath station is in a world heritage site and any works to the station regarding overhead line equipment or other disciplines would have a severe impact on the surrounding area. To help residents understand the impact of any changes, Network Rail commissioned a 3D model of the entire town extents. This was overlaid with the design proposal to provide a view from any location. The 3D model was present at most meetings with Bath planning authorities to allow flythrough, dimension checks and other key tasks (Figure 24).

Virtual design and construction was added to the model and much collaboration took place with the project management team, Hochtief and Tony Gee. No construction activity was authorised without being viewed in the 4D model.

Synchronised video was used to great effect at Bath station and was also available across the programme (Figure 25). A video survey was commissioned with each image having a geospatial

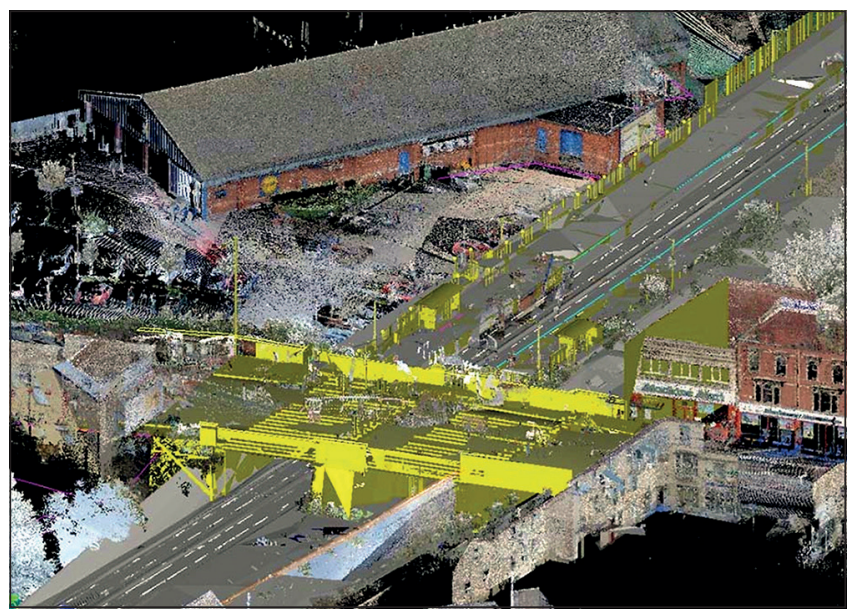

Figure 21. Example of hybrid view of point cloud and 3D model
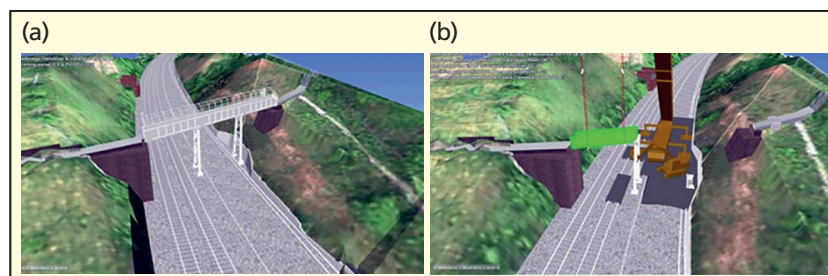

(c)

(d)
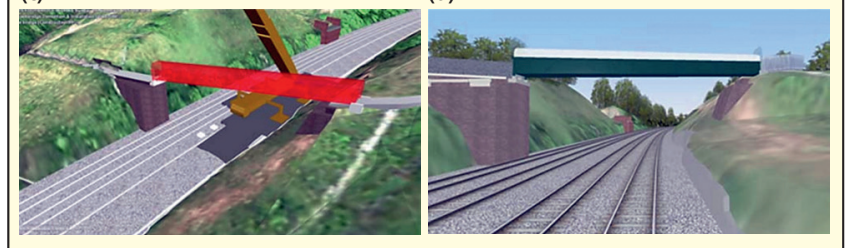

Figure 23. Example of Narroways footbridge 4D model: (a) existing bridge; (b) demolition sequence; (c) construction sequence; (d) install bridge 
location. This was then uploaded to the design tool to enable a photorealistic background from the driver's eye view.

\subsection{Bristol East junction renewals}

A lot of progress was made utilising signal-sighting and virtual design activities. At Bristol East junction renewals, train companies with the signalling designer, signal-sighting chairman and Network Rail project team agreed the location of the signal heads in a $3 \mathrm{D}$ model prior to signal designs or gantry designs being produced.

The advanced method allowed the signal designers to continue to design the signals and the gantry designer to design the gantry with drop-down cages. This saved an estimated 4 months of time on the programme (Figure 26).

\subsection{Buried services}

Buried services information was requested from Network Rail's national records group. This, combined with local data, was used to produce and manage buried services drawings and CAD models (Figure 27). The data consisted of a single

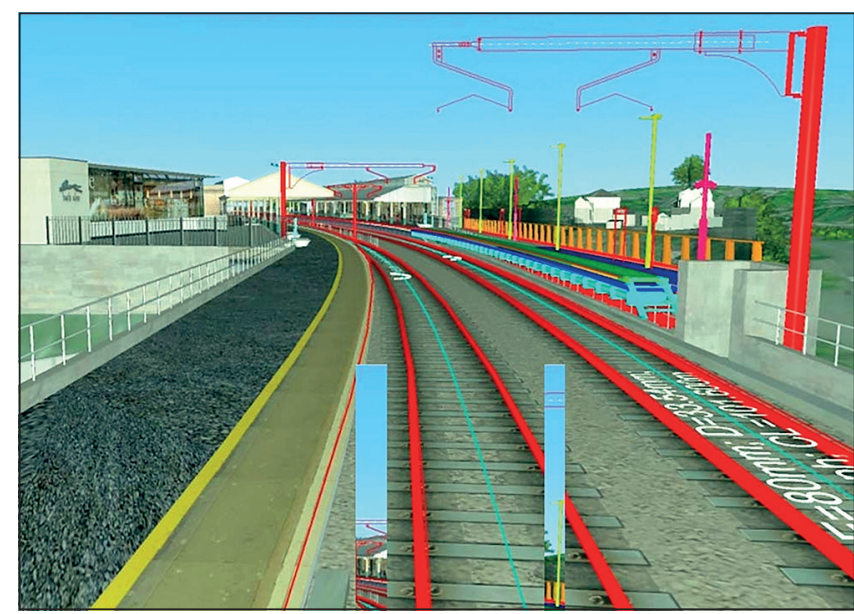

Figure 24. Virtual design and construction of Bath station

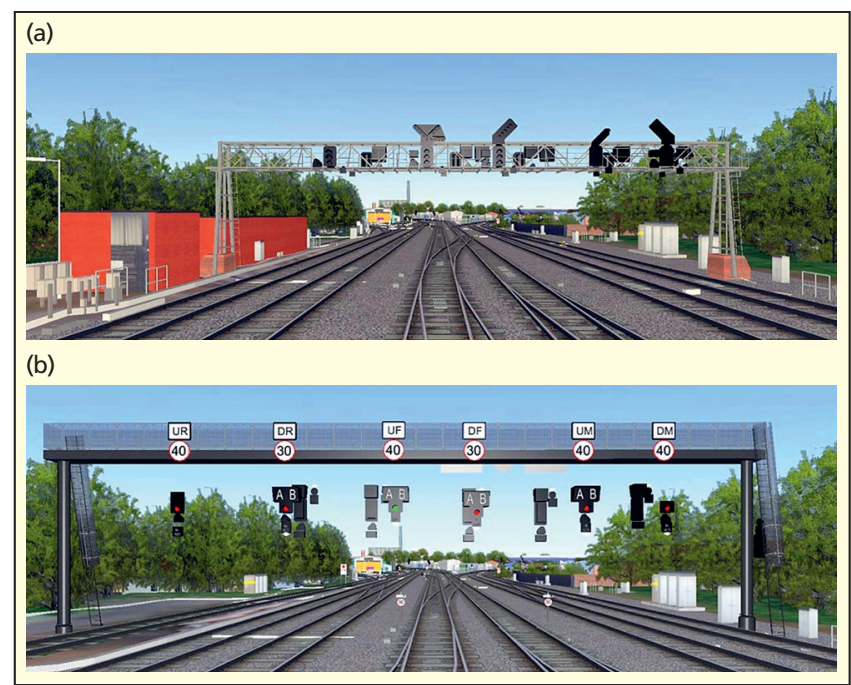

Figure 26. Bristol East junction renewals: (a) existing signal and sign gantry; (b) proposed signal gantry and sign configuration master model including data on: gas pipes, high- and lowvoltage electrical cables, historic cable routes, water pipes, culverts, surface and track drainage pipes, foul and clean sewers, telecoms cables, troughing, under-track crossings, CCTV cables, signalling cables and trial holes.

The engineering data management team examined the feasibility of adding inks to buried services data from EB at ground level so they were viewable in the $3 \mathrm{D}$ model. However, this was considered too time consuming considering the programme timescale.

\subsection{South Wales electrification}

In the Wales area, the same BIM standards and CDE successfully utilised in the Thames Valley and West of England areas were mandated. However, for the electrification design project, some suppliers did not understand the CDE workflow, version control or the submission of graphical data for every signal-sighting and interdisciplinary design review. Surveys were also being produced on different survey grids, despite a hands-on approach from Network Rail.

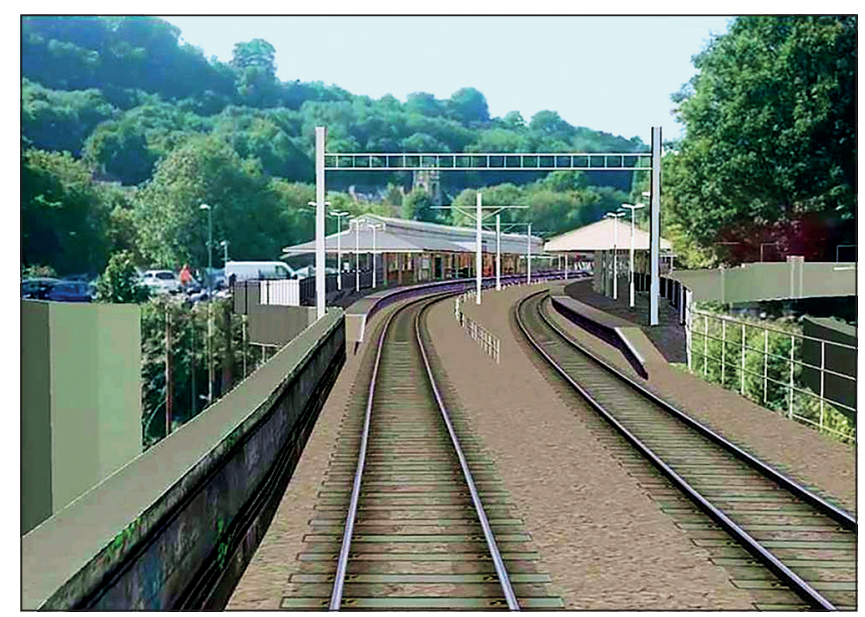

Figure 25. Synchronised video of Bath station

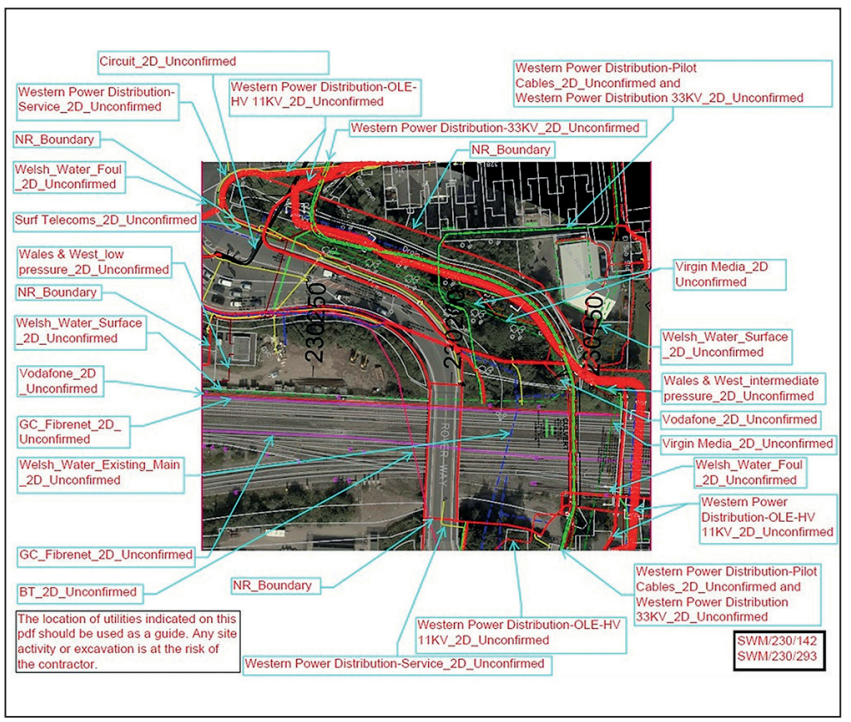

Figure 27. Extract of buried services model 
There was a derogation requested to the CAD standards, which became known locally as the 'six golden rules'. These were agreed and introduced so the supply chain would be aware of what would unblock signal-sighting reviews and interdisciplinary reviews.

The six golden rules were as follows.

- 3D/2D structures need to align (also to check foundation model).

- Suitability codes, revision history and alternative reference numbers all have to be correct.

- Reference file logical names need to be populated and should reflect the intent of the model.

- PDFs must match the drawing file.

- All files should be set to shared.

- A Network Rail CAD quality assurance report has to be included with each submission.

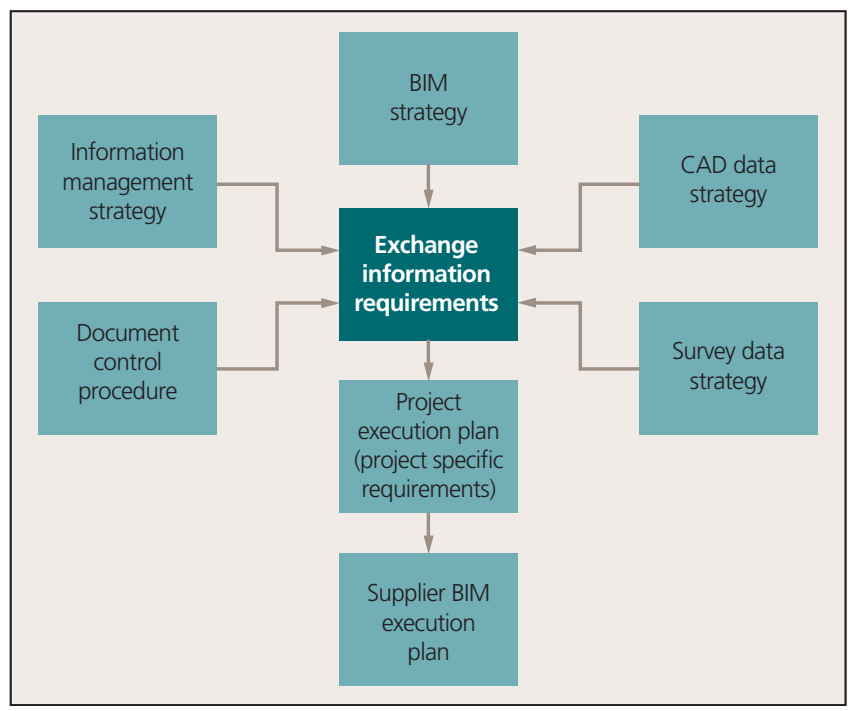

Figure 28. Network Rail Wales and Western BIM strategy

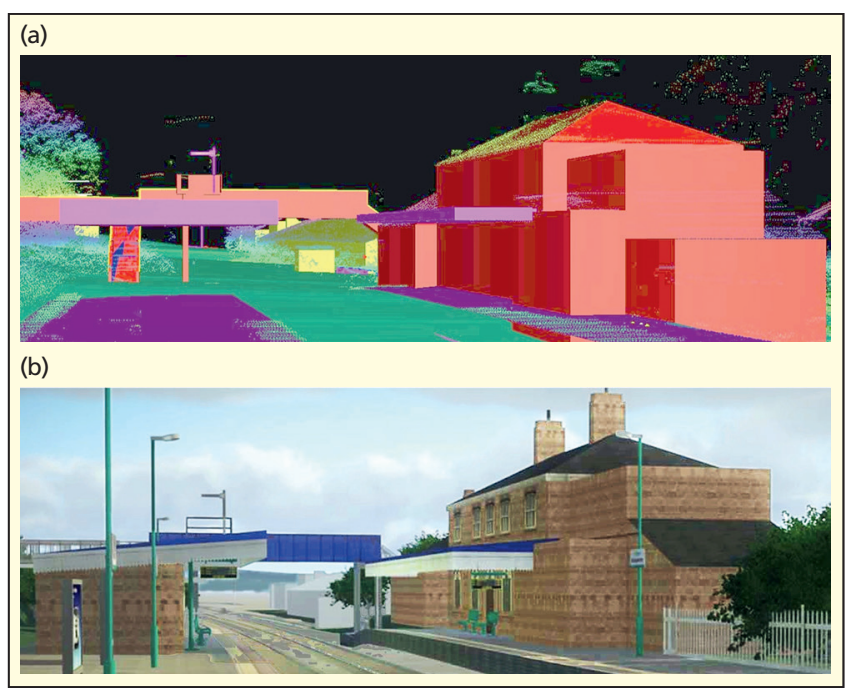

Figure 29. Development of 3D virtual model at Abergavenny station: (a) hybrid 3D model (CAD and point cloud); (b) full visualisation model
The engineering data management project surveyor resurveyed or validated any surveys that were not to standard. The south Wales immunisation signalling programme was delivered to BIM standard using the CDE. All reviews, including signal-sighting and interdisciplinary reviews, were produced using a 3D model.

\section{Wales and Western BIM strategy}

Based on lessons learned from the Greater West programme, Network Rail's Wales and Western region produced a BIM strategy outlining strategic goals for control period 6 (2019-2024) (Figure 28).

Exchange information requirements have been updated to reflect ISO 19650 (ISO, 2018) and added to contract requirements technical documents. They reflect a railway-specific project requirement with the correct roles and responsibility identified as described in Network Rail standard 02009 (Network Rail, 2015). The level of control will determine the BIM maturity of a project. Local work instructions have been developed for CAD, survey, information management, document control and BIM project execution plans.

Wales and Western is introducing a geographic information system for projects, which will be used by project teams to view the project information model. Route asset managers will identify opportunities to plan for hand-back from the start of a project and how this will add to the asset information model.

The use of digital twin technology and how this will impact the region are also being examined. Legacy project information management from the programme and Crossrail has left a virtual 3D model from Paddington to Cardiff, including via Bath to Bristol Temple Meads, and all supporting documentation in a CDE.

An ongoing strategic goal is to complete a $3 \mathrm{D}$ virtual model of the Western and Wales region. The 3D models are developed upon project start-up and can be used for any of the following:

- visualisation models for Grip 1-3 (Figure 29)

option selection

- driving the model at stakeholder meetings

- engineering integration of supplier designs

- representation of interdisciplinary checks and interdisciplinary reviews

- signal sighting

- clash avoidance

- creation of $3 \mathrm{D}$ animations

- planning application drawings

- site-applied augmented reality.

\section{References}

BSI (2007) BS 1192:2007+A2:2016: Collaborative production of architectural, engineering and construction information. Code of practice. BSI, London, UK.

ISO (International Organization of Standardization) (2018) ISO 19650:2018: Organization and digitization of information about buildings and civil engineering works, including building information modelling (BIM) information management using building information modelling. ISO, Geneva, Switzerland.

Murray S (2014) WAW IMS 866: Wales and Western route survey strategy. Network Rail, London, UK

Network Rail (2015) NR/L2/INI/02009: Issue 6. Engineering management for projects. Network Rail, London, UK. 